\title{
Independent evolutionary origins of landlocked alewife populations and rapid parallel evolution of phenotypic traits
}

\author{
ERIC P. PALKOVACS, ${ }^{*}$ KIRSTIN B. DION,+ DAVID M. POST* and ADALGISA CACCONE*† \\ *Department of Ecology and Evolutionary Biology, Yale University, 165 Prospect Street, New Haven, CT 06520-8106, USA, \\ +Molecular Systematics and Conservation Genetics Laboratory, Yale Institute for Biospheric Studies, 21 Sachem Street, New Haven, \\ CT 06520-8105, USA
}

\begin{abstract}
Alewife, Alosa pseudoharengus, populations occur in two discrete life-history variants, an anadromous form and a landlocked (freshwater resident) form. Landlocked populations display a consistent pattern of life-history divergence from anadromous populations, including earlier age at maturity, smaller adult body size, and reduced fecundity. In Connecticut (USA), dams constructed on coastal streams separate anadromous spawning runs from lake-resident landlocked populations. Here, we used sequence data from the mtDNA control region and allele frequency data from five microsatellite loci to ask whether coastal Connecticut landlocked alewife populations are independently evolved from anadromous populations or whether they share a common freshwater ancestor. We then used microsatellite data to estimate the timing of the divergence between anadromous and landlocked populations. Finally, we examined anadromous and landlocked populations for divergence in foraging morphology and used divergence time estimates to calculate the rate of evolution for foraging traits. Our results indicate that landlocked populations have evolved multiple times independently. Tests of population divergence and estimates of gene flow show that landlocked populations are genetically isolated, whereas anadromous populations exchange genes. These results support a 'phylogenetic raceme' model of landlocked alewife divergence, with anadromous populations forming an ancestral core from which landlocked populations independently diverged. Divergence time estimates suggest that landlocked populations diverged from a common anadromous ancestor no longer than 5000 years ago and perhaps as recently as 300 years ago, depending on the microsatellite mutation rate assumed. Examination of foraging traits reveals landlocked populations to have significantly narrower gapes and smaller gill raker spacings than anadromous populations, suggesting that they are adapted to foraging on smaller prey items. Estimates of evolutionary rates (in haldanes) indicate rapid evolution of foraging traits, possibly in response to changes in available resources.
\end{abstract}

Keywords: Alosa pseudoharengus, anadromous, divergence time, evolutionary rate, gill rakers, parallel evolution

Received 20 April 2007; revision received 28 August 2007; accepted 25 September 2007

\section{Introduction}

When different populations exhibit similar adaptive traits, it is of interest to ecologists and evolutionary biologists to discern whether these traits arose once and are the result of

Correspondence: Eric P. Palkovacs, School of Biology and Ecology, University of Maine, Orono, ME 04469-5751, USA. Fax: +1207 581 2537; E-mail: eric.palkovacs@maine.edu shared ancestry or whether they arose multiple times and are the result of parallel evolution. Testing for parallel evolution is important in studies of adaptation in natural populations because the presence of similar traits in different lineages points to natural selection as a likely cause of phenotypic evolution (Harvey \& Pagel 1991; Schluter et al. 2004). Ecologically important traits, in particular, are likely to converge across distinct lineages if they are repeatedly favoured by natural selection in similar environments 
(Endler 1986; Losos et al. 1998; Rundle et al. 2000). Here, we examined populations of anadromous and landlocked (freshwater resident) alewife, Alosa pseudoharengus, populations in Connecticut (USA), which display consistent patterns of phenotypic divergence, to determine whether independent evolutionary origins of landlocked populations have resulted in the parallel evolution of phenotypic traits.

Anadromous alewives are native to the east coast of North America from North Carolina to Labrador (Scott \& Crossman 1973). In Connecticut, anadromous alewife spawning runs occur in most streams and rivers with access to Long Island Sound, although at densities far below historical levels (Davis 2004). Anadromous alewife spawning in Connecticut occurs between late March and early June (Kissil 1974), and young-of-the-year (YOY) spend several months feeding in freshwater before migrating to the ocean between July and November (Richkus 1975; Yako et al. 2002).

Anadromy is the ancestral life-history strategy in the alewife (Faria et al. 2006); however, some alewife populations have lost the marine phase of their life cycle and spend their entire lives in freshwater lakes. Although best known for their invasion of the Laurentian Great Lakes following canal construction in the 1820s and 1830s (Scott \& Crossman 1973; Ihssen et al. 1992; Mills et al. 1993; Kuhn 2004), these landlocked populations can also thrive in relatively small lakes and ponds. Unlike anadromousfreshwater resident population pairs of some other fish species which spawn in sympatry [e.g. sockeye salmon and kokanee, Oncorhynchus nerka (Wood \& Foote 1990; Wood \& Foote 1996) and three-spined sticklebacks, Gasterosteus aculeatus (McPhail 1994; McKinnon \& Rundle 2002; McKinnon et al. 2004)], anadromous and landlocked alewife populations do not typically co-exist in the same lakes.

In Connecticut, the majority of landlocked alewife populations were intentionally stocked from a single source population as forage for game fish, but populations with no records of having been stocked currently exist in a handful of lakes in the southern half of the state (Phillips et al. 1987). Dams built during early European colonization (between 1630 and 1800), or their modern replacements, separate these unstocked, potentially locally evolved, landlocked alewife populations from downstream anadromous populations. Despite the potential for some coastal landlocked alewife populations to be locally evolved, and therefore native, unfavourable management consequences of past stocking efforts have led to the common belief that all landlocked alewife populations in Connecticut are nonnative (Jacobs \& O'Donnell 2002).

Differences in the relative amounts of time spent in marine vs. freshwater environments drive substantial lifehistory divergence between anadromous and landlocked alewife populations. Compared to anadromous alewives, landlocked alewives exhibit earlier age at maturity, slower adult growth, smaller size at maturity, a more pronounced decrease in individual growth rate following maturation, and an overall smaller size-at-age (Graham 1956). In accordance with their smaller body size, landlocked females tend to show reduced fecundity relative to anadromous females (Scott \& Crossman 1973). Differences in life-history traits between anadromous and landlocked populations have likely evolved in response to differences in the growth potentials offered by marine and freshwater environments (Hendry et al. 2004).

Landlocked alewife populations may experience strong selection on foraging traits that may also have caused these traits to diverge from anadromous populations. Landlocked alewives can feed in a selective manner that targets the largest zooplankton prey available (Janssen 1976). In doing so, landlocked populations can force changes in zooplankton communities that reduce average zooplankton body size (Brooks \& Dodson 1965; Wells 1970; Hutchinson 1971; Warshaw 1972; Harman \& Albright 2002). After overexploiting large prey, landlocked alewives may experience strong selection for foraging on smaller prey items. This shift in prey size may ultimately shape the evolution of foraging traits such as gape width and gill raker spacing, which are important for size-selective prey capture in planktivorous fishes (Drenner et al. 1984; Mummert \& Drenner 1986; Lazzaro 1987; Gibson 1988; MacNeill \& Brandt 1990; Robinson \& Wilson 1994).

For this study, we used mtDNA and microsatellite data to infer the pattern of population-level relationships between upstream landlocked and downstream anadromous population pairs to determine whether landlocked populations evolved independently from anadromous ancestors or are derived from a common freshwater resident population. Next, we used microsatellite data to examine the time frame of the divergence between anadromous and landlocked populations. Finally, we examined whether anadromous and landlocked alewife populations have diverged in foraging morphology and used divergence time estimates to calculate the rate of evolution for these traits.

\section{Materials and methods}

\section{Alewife sampling}

Anadromous and landlocked alewives were collected from paired sampling sites in Connecticut $\left(41^{\circ} \mathrm{N}, 72^{\circ} \mathrm{W}\right)$ during the spring and summer of 2004 and 2005 (Fig. 1). Anadromous alewives were collected from spring spawning runs at seven sites: Farm River (FR), West River (WR), Mill Creek (MC), Bride Brook (BB), Pattagansett River (PR), Poquetanuck River (POR), and Whitford Brook (WB). In addition, anadromous YOY were sampled from three nursery lakes: Dodge Pond (DP), Gorton Pond (GP), and Bride Lake (BL). The DP and GP populations are within the same watershed and directly upstream of the PR sampling site, and BL is 


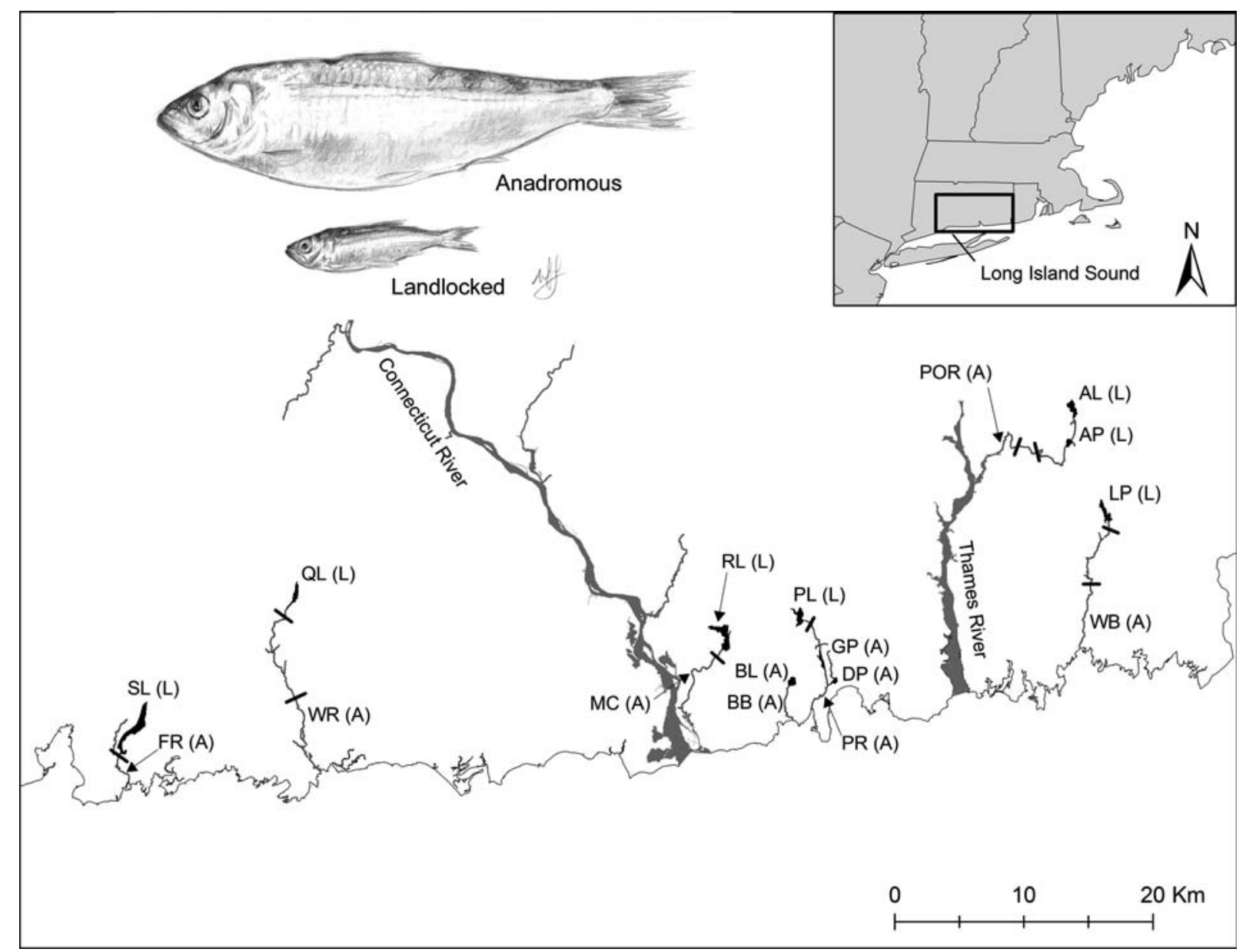

Fig. 1 Sampling sites for anadromous (A) and landlocked (L) alewife populations in Connecticut, USA. Within drainages, dams (indicated by solid black lines) separate anadromous and landlocked populations.

directly upstream of the BB site. Landlocked alewives were collected from seven lakes: Saltonstall Lake (SL), Quonnipaug Lake (QL), Rogers Lake (RL), Pattagansett Lake (PL), Amos Lake (AL), Avery Pond (AP), and Long Pond (LP). $\mathrm{AL}$ and $\mathrm{AP}$ are within the same drainage, and there are no barriers to migration between them. With the exception of the $\mathrm{BB}$ run, all anadromous runs occur downstream of landlocked populations. At least 20 fish were collected at each site, with the exception of FR $(n=8)$ and WR $(n=10)$, where we were unable to capture 20 alewives. Alewife sampling was conducted under the Yale University Institutional Animal Care \& Use Committee Protocol \# 2003-10734 and the State of Connecticut Department of Environmental Protection Scientific Collector Permit \#SC-04016. Anadromous alewives were collected by beach seine, basket trap, and, in the case of the BB site, a weir constructed and operated by the Connecticut Department of Environmental Protection to monitor the spawning run (Davis 2004). Landlocked alewives and anadromous YOY were collected from lakes using a purse seine, gill net, or electrofishing boat. All alewives were immediately placed on ice before being frozen at $-20{ }^{\circ} \mathrm{C}$ for storage.

\section{Mitochondrial DNA}

Total genomic DNA was extracted from $\sim 25 \mathrm{mg}$ of frozen muscle tissue using the DNeasy Tissue Kit and animal tissue protocol (QIAGEN). A 599-bp fragment of the control region (CR1) was amplified using the primer pair $B$ and $Q$ (Lee et al. 1995). This portion of the control region lies adjacent to the tRNA-Pro gene and is highly variable in fishes (Lee et al. 1995).

Polymerase chain reactions (PCR) were performed in an MJ Research PTC-200 Peltier Thermocycler, using $50 \mu \mathrm{L}$ volumes containing 1-2 $\mu \mathrm{L}$ unquantified genomic DNA, $5 \mu \mathrm{L} 10 \times$ PCR buffer (Applied Biosystems), 1 mm dNTPs, $2.5 \mathrm{mM} \mathrm{MgCl}_{2}, 1.5 \mu \mathrm{L}$ BSA, $0.3 \mu \mathrm{M}$ of each primer and $0.5 \mathrm{U}$ AmpliTaq Gold (Applied Biosystems). Thermal cycler conditions consisted of an initial denaturation step at $94{ }^{\circ} \mathrm{C}$ for $10 \mathrm{~min}$, followed by 35 cycles of denaturation for $1 \mathrm{~min}$ at 
$94{ }^{\circ} \mathrm{C}$, annealing for $1 \mathrm{~min}$ at $52{ }^{\circ} \mathrm{C}$ and extension for $1 \mathrm{~min}$ at $72{ }^{\circ} \mathrm{C}$. The last cycle included a final extension at $72{ }^{\circ} \mathrm{C}$ for $5 \mathrm{~min}$. To verify size and purity, $5 \mu \mathrm{L}$ of PCR products and negative controls were visualized on $1 \%$ agarose gels stained with ethidium bromide. Reactions were cleaned with the QIAquick PCR Purification Kit (QIAGEN).

Sequencing was carried out using an ABI 3730 automated DNA sequencer. To promote accuracy, fragments were sequenced in both directions using primers $\mathrm{B}$ and $\mathrm{Q}$. Complementary mitochondrial DNA strands were aligned and edited with SEQUENCHER 4.2.2 (Gene Codes Corporation). Any samples giving problematic sequences containing either base ambiguities or missing data were subjected to a second round of DNA extraction, PCR, and sequencing. Only sequences containing unambiguous data were included in downstream analyses. All unique haplotype sequences were submitted to GenBank (accession nos EF455824-EF455856).

In addition to the CR1 region, we sequenced portions of the cytochrome $b$ (cyt $b, 396 \mathrm{bp}$ ), $16 \mathrm{~S}$ (547 bp), and 12S (363 bp) rRNA genes for eight individuals representing four populations and both life histories to look for fixed sequence differences between alewives exhibiting the landlocked and anadromous life-history forms. Cyt $b$ was amplified and sequenced with the primer pair cyt $b$ B2 (Kocher et al. 1989) and cyt $b$ GLU (Pääbo 1990). 12S was amplified and sequenced with the primer pair L1091 and H1478 (Kocher et al. 1989), and 16S was amplified and sequenced with the primer pair 16Sar and 16Sbr (Palumbi et al. 1991). PCR conditions were according to Caccone $e t$ al. (1999). PCR purification, sequencing, and sequence editing were as described above. Sequences were submitted to GenBank (accession nos EF455858-EF455863).

Chromatograms were re-examined to validate all instances of variability. Cyt $b$ sequences were invariant and $12 \mathrm{~S}$ and $16 \mathrm{~S}$ sequences did not show any fixed differences between anadromous and landlocked populations. Therefore, these markers were not examined further. CR1 sequences were aligned with CLUSTAL $\mathrm{w}$ (Thompson et al. 1994) and checked by eye. ARLEQUIN 2.0 (Schneider et al. 2000) was used to determine the number of haplotypes per population $(\mathrm{H})$, and to estimate the haplotype diversity $(h)$, the mean number of pairwise differences between all pairs of haplotypes $(\pi)$, and the nucleotide diversity $\left(\pi_{\mathrm{n}}\right)$ for each population. ANOva was used to test whether mean values for diversity indices $\left(\mathrm{H}, h, \pi\right.$, and $\left.\pi_{\mathrm{n}}\right)$ differed significantly between landlocked and anadromous populations (applied using sPSs 11.0). TCs 1.21 (Clement et al. 2000) was used to construct a CR1 haplotype network based on statistical parsimony. Gaps were treated as fifth state data and instances of haplotype looping were resolved using predictions from coalescent theory (Crandall \& Templeton 1993; Posada \& Crandall 2001). Analysis of molecular variance (AMOvA) was used to partition control region variation into differ- ences between groups, differences among populations within groups, and differences within populations (Excoffier et al. 1992). AMOva was conducted with anadromous and landlocked population groups and with within-watershed population groups. Additionally, pairwise $F_{\mathrm{ST}}$ values and exact tests of population differentiation (Raymond \& Rousset 1995a) were performed in ARLEQUIN 2.0 to assess differentiation among populations.

\section{Microsatellites}

Genotypic data for the six landlocked-anadromous population pairs plus the anadromous BB population were collected for six microsatellite loci. We used loci initially developed for Alosa sapidissima (ASA2, ASA8, ASA9; Waters et al. 2000), Alosa alosa (AA14; Faria et al. 2004), and Alosa fallax (AF13, AF20; Faria et al. 2004). Twenty specimens were genotyped per population except for FR $(n=8)$ and WR $(n=10)$. AP and DP/GP were excluded from the microsatellite analysis because they are not physically separated from AL and PR, respectively, and therefore probably exchange many migrants. PCRs were carried out in $10 \mu \mathrm{L}$ volumes composed of $1.5 \mu \mathrm{L}$ template DNA, $1 \mu \mathrm{L}$ 10× buffer (Applied Biosystems), $1 \mathrm{~mm}$ dNTP mix, $2 \mathrm{~mm}$ $\mathrm{MgCl}_{2}, 1 \mu \mathrm{M}$ of each primer, and $0.5 \mathrm{U}$ of AmpliTaq Gold (Applied Biosystems). Amplifications were performed in an MJ Research PTC-200 Peltier Thermocycler and consisted of an initial 10-min denaturation step at $94{ }^{\circ} \mathrm{C}$ followed by 35 cycles of denaturation for $1 \mathrm{~min}$ at $94^{\circ} \mathrm{C}$, annealing for $1 \mathrm{~min}$ at locus-specific temperatures, extension for $1 \mathrm{~min}$ at $72{ }^{\circ} \mathrm{C}$, and a final 2-min extension period at $72{ }^{\circ} \mathrm{C}$. PCR products were run on an ABI 3730 with ROX 500 size standard, and allele sizes were assigned with the software GENEMAPPER 3.7 (Applied Biosystems).

The locus ASA2 was monomorphic for the same allele in all samples examined and was excluded from all analyses. The number of alleles $\left(N_{\mathrm{a}}\right)$, the observed heterozygosity $\left(H_{\mathrm{O}}\right)$, the expected heterozygosity $\left(H_{\mathrm{E}}\right)$, and the inbreeding coefficient for individuals $\left(F_{\mathrm{IS}}\right)$ were calculated using GENEPOP 3.4 (Raymond \& Rousset 1995b), as were tests for departure from genotypic linkage disequilibrium and Hardy-Weinberg equilibrium (HWE). ANOvA was used to test for differences in mean $N_{\mathrm{a}}$ and $H_{\mathrm{O}}$ between the two life histories (applied using spss 11.0). The presence of null alleles was examined using the program MICRO-CHECKER (van Oosterhout et al. 2004). $F_{\mathrm{ST}}$ was calculated according to Weir \& Cockerham (1984) and its significance evaluated using the permutation procedure implemented in GENETIX 4.05 (Belkhir et al. 1996-2004). $F_{\mathrm{ST}}$ measures were subjected to nonmetric multidimensional scaling (NMDS) and plotted in two dimensions (applied using sPss 11.0). Tests of genotypic homogeneity were performed using a log-likelihood (G)-based exact test (Goudet et al. 1996) implemented in GENEPOP 3.4. This procedure tests the null hypothesis 
that the genotypic distribution is identical across populations. The program STRUCTURe 2.1 (Pritchard et al. 2000) was used to identify the most likely number of natural group$\operatorname{ings}(K)$ for $K=2$ through 13 . We conducted STRUCTURE test runs at various burn-in values and Markov chain Monte Carlo (MCMC) run lengths. Our final analysis used a burnin of 10000 and 100000 MCMC repetitions. Gene flow between populations $\left(N_{\mathrm{m}}\right)$ was calculated according to the private alleles method (Slatkin 1985; Barton \& Slatkin 1986) using GENEPOP 3.4.

\section{Combined mtDNA and microsatellite analyses}

To determine whether landlocked populations are more closely related to each other than to anadromous populations, we examined within- and between-life-history variation using mean $F_{\mathrm{ST}}$ values. Although pairwise $F_{\mathrm{ST}}$ values calculated from a single marker are not truly independent of each other (because the same populations are used in multiple comparisons), mean $F_{\mathrm{ST}}$ values calculated from multiple unlinked markers provide independent measures of genetic divergence. Therefore, using the six independent loci as replicates (CR1 plus five microsatellite loci), we applied ANOva and post-hoc Tukey tests to ask whether the average amount of differentiation between all possible within-life-history population pairs (anadromousanadromous and landlocked-landlocked) was significantly different from the average amount of differentiation between all possible between-life-history population pairs (anadromous-landlocked).

To better understand the pattern of relatedness among anadromous populations, we examined these populations for evidence of isolation by distance. Using ARCMAP 9.1 (ESRI) and GIS data from the Connecticut Department of Environmental Protection (CT DEP, Environmental GIS Data for Connecticut 2005), we calculated the geographical distance between the mouths of anadromous alewife streams (the points at which these streams enter Long Island Sound). We conducted Mantel tests to examine the relationships between geographical distances and pairwise $F_{\mathrm{ST}}$ values for mtDNA and microsatellite data. For each Mantel test, 1000 permutations were performed using ARLEQUIN 2.0 to assess the significance of the correlation between the geographical distance matrix and the pairwise $F_{\mathrm{ST}}$ matrix.

\section{Divergence time}

To estimate the time since landlocking, we applied the method used by Raeymaekers et al. (2005) to estimate the divergence time for independently derived freshwater populations of three-spined sticklebacks. This method, based on Jin \& Chakraborty's (1995) $G_{\mathrm{ST}}$ estimation for hypervariable loci under an infinite allele model of molecular evolution, can be used to predict the time in generations since divergence $(t)$ as a function of $G_{\mathrm{ST}}$, the effective population size $\left(N_{e}\right)$, the number of populations (s), the size of populations $\left(N_{k}\right)$, and their observed heterozygosity $\left(H_{\mathrm{O}}\right)$. Although an infinite allele model is mechanistically unrealistic for microsatellites, we favour it here because it is simple and robust, and because several of our loci did not to conform to stepwise predictions. An assumption of this divergence estimation method is that no gene flow occurs between populations, which is likely to hold for the landlocked alewife populations examined in this analysis.

$N_{k}$ was estimated for each of the $s=6$ landlocked alewife populations based on an average density of 0.47 alewives / $\mathrm{m}^{2}$ multiplied by the area of each lake. To arrive at this density estimate, lakes containing landlocked populations (PL, $\mathrm{QL}$, and RL) were each sampled on five different sampling dates between June and September 2005 using a fixed-area pelagic purse seine that encircles an area of $100 \mathrm{~m}^{2}$. Three to five sets per sampling bout were performed and sets were placed haphazardly at night, when alewives move up and spread out in the water column, in an attempt to avoid any bias caused by schooling behaviour. Density estimates for each lake-date sample are provided in Palkovacs (2007).

$N_{e}$ for landlocked populations was calculated according to Crow \& Kimura (1970) for relatively fast $\left(\mu_{\mathrm{f}}=10^{-3}\right)$ and slow $\left(\mu_{\mathrm{s}}=10^{-4}\right)$ microsatellite mutation rates (Ellegren 2000). Ninety-five percent confidence intervals were placed $N_{e}$ estimates to account for uncertainty in measures of $H_{\mathrm{O}}$. $G_{\mathrm{ST}}$ for landlocked populations was calculated based on the unbiased estimator of Nei \& Chesser (1983), which yielded a $G_{\mathrm{ST}}$ of 0.2811 . Based on these parameters, we solved for $t$, the number of generations since landlocked populations diverged from a common anadromous ancestor.

\section{Phenotypic divergence}

To assess differences in adult body size between anadromous and landlocked populations, we measured alewife total length to the nearest millimetre. Differences in total length ( $\log _{10}$ transformed) between anadromous and landlocked populations were evaluated using mixed-effects ANOvA, with population (considered as a random effect) nested within life-history type (anadromous or landlocked).

To examine differences in feeding morphology between anadromous and landlocked alewife populations, we measured gape width and average gill raker spacing for YOY alewives between $60 \mathrm{~mm}$ and $80 \mathrm{~mm}$ total length from three anadromous (BL, DP, GP) and three landlocked populations (PL, QL, RL). Gape and gill raker traits are strongly influenced by body size (Gibson 1988; MacNeill \& Brandt 1990; Friedland et al. 2006). By measuring common age and size fish sampled in the freshwater environment, we hoped to minimize the impact of plasticity in individual growth rate on trait differences. Anadromous YOY can be reliably 
Table 1 Diversity indices for mtDNA control region data. The number of haplotypes $(H)$, haplotype diversity $(h)$, mean number of pairwise differences between haplotypes $(\pi)$, and nucleotide diversity $\left(\pi_{\mathrm{n}}\right)$ are given for each population and mean values are given for each life history

\begin{tabular}{llllll}
\hline Population & Sample size & $H$ & $h$ & $\pi$ & $\pi_{\mathrm{n}}$ \\
\hline FR (A) & 8 & 6 & 0.9286 & 3.4643 & 0.0059 \\
WR (A) & 10 & 9 & 0.9778 & 5.7556 & 0.0096 \\
MC (A) & 10 & 8 & 0.9556 & 3.4889 & 0.0059 \\
BB (A) & 10 & 6 & 0.8444 & 4.4222 & 0.0074 \\
GP (A) & 10 & 6 & 0.8667 & 3.6667 & 0.0062 \\
DP (A) & 10 & 6 & 0.7778 & 3.7556 & 0.0063 \\
PR (A) & 10 & 6 & 0.7778 & 3.3333 & 0.0056 \\
POR (A) & 10 & 7 & 0.9111 & 3.1778 & 0.0054 \\
WB (A) & 10 & 4 & 0.6444 & 1.6444 & 0.0028 \\
Anadromous & & 6.44 & 0.8538 & 3.6343 & 0.0061 \\
SL (L) & 10 & 3 & 0.6444 & 2.4222 & 0.0041 \\
QL (L) & 10 & 4 & 0.5333 & 1.8000 & 0.0030 \\
RL (L) & 10 & 3 & 0.6000 & 3.4667 & 0.0057 \\
PL (L) & 10 & 4 & 0.6444 & 5.2444 & 0.0088 \\
AL (L) & 10 & 3 & 0.6000 & 4.1333 & 0.0069 \\
AP (L) & 10 & 4 & 0.7111 & 2.8667 & 0.0048 \\
LP (L) & 10 & 3 & 0.7111 & 4.9778 & 0.0083 \\
Landlocked & & 3.43 & 0.6349 & 3.5587 & 0.0059 \\
\hline
\end{tabular}

sampled from nursery lakes but not from streams (where they are rapidly transported downstream by high flow). Therefore, our examination of foraging traits was restricted to a subset of the total number of populations sampled for genetic analysis.

To measure gape width, the mouth of each fish was opened to its maximum extent and the gape was measured at its widest point. To measure gill raker spacing, the first branchial arch on the left side of each fish was removed and examined under a dissecting microscope. The first arch was examined because this arch has the most highly developed gill rakers and performs the majority of the filtering in alewives (MacNeill \& Brandt 1990). Gill raker spacing was not measured directly because of the tendency for gill rakers to become stuck together in preserved fish. Instead, average gill raker spacing (GRS) was estimated as GRS $=(L-$ $N^{*} W$ )/ $N$ where $N$ is the total gill raker number, $L$ is the sum of the lengths of the upper and lower gill arches, and $W$ is the average of the widths of the first gill rakers on the upper and lower gill arches. Differences in gape width $\left(\log _{10}\right.$ transformed) and gill raker spacing were evaluated using mixed-effects ANOvA with population (considered as a random effect) nested within life-history type (conducted in SPSS 11.0).

\section{Rates of evolution}

Foraging traits in planktivorous fishes are known to experience strong selection and may evolve rapidly in response to changing ecological conditions (Lindsey 1981; Bernatchez et al. 1999; Lu \& Bernatchez 1999; Bernatchez 2004; Ostbye et al. 2006). Using the results of our genetic analysis to infer the timing of landlocking in alewife populations, we estimated the rate of evolution for gape width and gill raker spacing for the three landlocked populations examined ( $\mathrm{PL}, \mathrm{QL}$, and RL). Because genetic data suggested gene flow among anadromous populations, we estimated the rate of trait divergence for each landlocked population relative to pooled data from three anadromous populations (BL, DP, and GP). Evolutionary rates for In transformed data were estimated in haldanes, which specify rates in standard deviations per generation (Gingerich 1993). Because our data were collected simultaneously, in the field, for different populations sharing a common ancestor, we estimated the rate of phenotypic divergence rather than the rate of evolution per se (Hendry \& Kinnison 1999). However, our estimate is probably close to the rate of evolution in landlocked populations because evolutionary changes likely occurred principally within landlocked populations (and not in anadromous populations) as these populations adapted to novel ecological conditions (Reznick \& Ghalambor 2001).

\section{Results}

\section{Mitochondrial DNA}

CR1 sequences indicated the presence of 33 distinct haplotypes. Tests for differences in diversity indices revealed that, compared to landlocked populations, anadromous populations had significantly higher values for $\mathrm{H}\left(F_{1,14}=\right.$ 27.954, $P<0.001)$ and $h\left(F_{1.14}=23.004, P<0.001\right)$, but not for $\pi\left(F_{1,14}=0.016, P=0.901\right)$ or $\pi_{\mathrm{n}}\left(F_{1,14}=0.033, P=0.858\right)$, indicating that landlocked populations possess a subsample of the contemporary haplotypes found in anadromous populations (Table 1). The haplotype network structure revealed extensive haplotype sharing between anadromous and landlocked populations (Fig. 2). Therefore, mtDNA sequence data showed no evidence for a deep phylogenetic split between the anadromous and landlocked life histories that would indicate different glacial lineages (Avise 2000). A 7-bp gap divides the network, but four out of six landlocked populations contain haplotypes on both sides of this gap.

AMOVA, conducted on CR1 haplotypes to examine structuring within and between anadromous and landlocked population groups, indicated that $54 \%$ of genetic variation existed within populations $(P<0.00001), 26 \%$ among populations within groups (anadromous and landlocked) $(P<0.00001)$, and $20 \%$ among groups $(P=0.0039)$. AMOva conducted to examine within-watershed population groups indicated that $59 \%$ of the variation existed within populations $(P<0.00001), 40 \%$ among populations within groups (watersheds) $(P<0.0001)$, and $1 \%$ among groups $(P=$ 


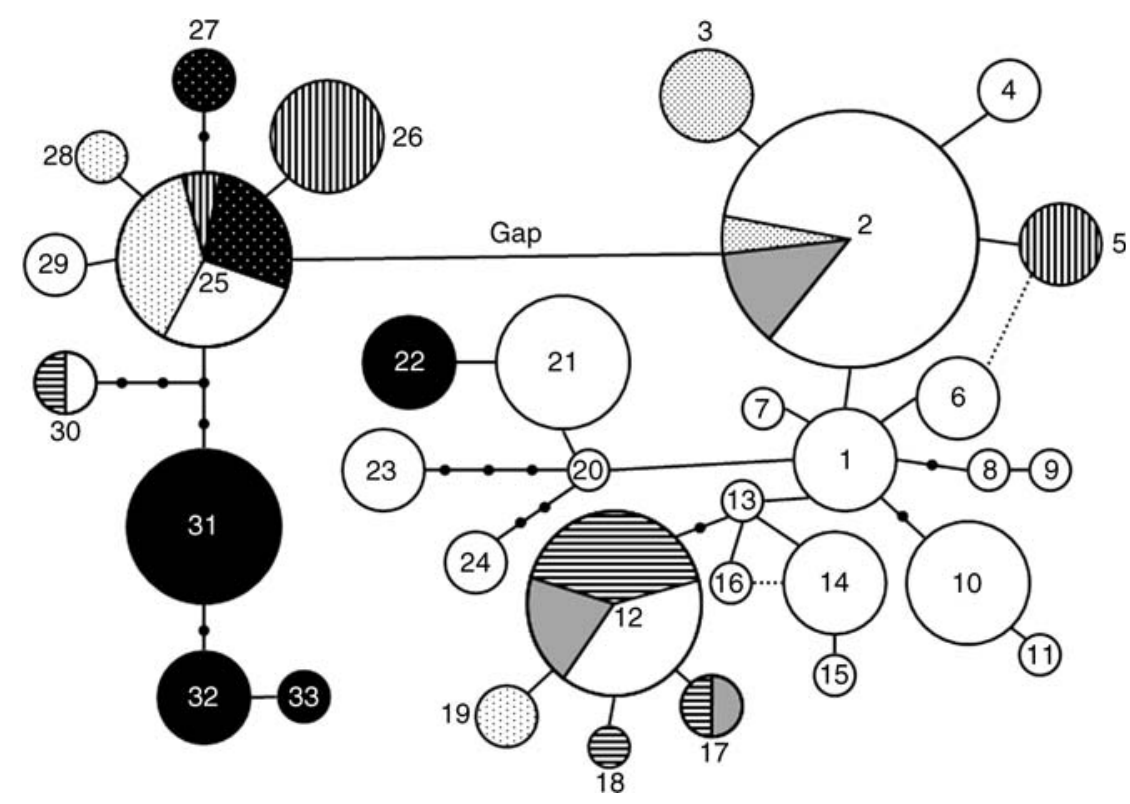

Fig. 2 Haplotype network based on 599 bp of the mtDNA control region (CR1). The sizes of the circles represent the relative numbers of individuals with a given haplotype. All anadromous samples are shown in white. Landlocked populations are shown using different fills, representing different populations $($ black $=\mathrm{AL} / \mathrm{AP}$, grey $=\mathrm{SL}$, black stippling on white $=$ PL, white stippling on black $=\mathrm{LP}$, vertical stripes $=\mathrm{RL}$, horizontal stripes $=Q L$ ). A 7-bp gap differentiates haplotypes 1-24 from haplotypes 25-33.

Table $2 P$-values for genotypic tests of homogeneity based on microsatellites (above diagonal) and exact tests of genetic differentiation based on mtDNA (below diagonal). Landlocked populations are frequently (mtDNA) or always (microsatellites) significantly differentiated from other populations, whereas anadromous populations are not (with a single exception) significantly differentiated from each other. Tests that are significant after Bonferroni correction are in bold

\begin{tabular}{|c|c|c|c|c|c|c|c|c|c|c|c|c|c|c|}
\hline & & \multicolumn{7}{|c|}{ Anadromous } & \multicolumn{6}{|c|}{ Landlocked } \\
\hline & & FR & WR & $\mathrm{MC}$ & BB & PR & POR & WB & SL & QL & RL & PL & AL & LP \\
\hline \multirow[t]{7}{*}{ Anadromous } & FR & - & 0.0445 & 0.4415 & 0.5035 & 0.0134 & 0.0650 & 0.3401 & $<0.0001$ & $<0.0001$ & $<0.0001$ & $<0.0001$ & $<0.0001$ & $<0.0001$ \\
\hline & WR & 0.9061 & - & 0.0057 & 0.0532 & 0.0001 & 0.0212 & 0.0032 & $<0.0001$ & $<0.0001$ & $<0.0001$ & $<0.0001$ & $<0.0001$ & $<0.0001$ \\
\hline & $\mathrm{MC}$ & 0.6463 & 0.8794 & - & 0.5861 & 0.0108 & 0.5943 & 0.1945 & $<0.0001$ & $<0.0001$ & $<0.0001$ & $<0.0001$ & $<0.0001$ & $<0.0001$ \\
\hline & $\mathrm{BB}$ & 0.4938 & 0.9669 & 0.5406 & - & 0.0061 & 0.7859 & 0.3762 & $<0.0001$ & $<0.0001$ & $<0.0001$ & $<0.0001$ & $<0.0001$ & $<0.0001$ \\
\hline & PR & 0.2133 & 0.8031 & 0.1586 & 0.8490 & - & 0.0245 & 0.1723 & $<0.0001$ & $<0.0001$ & $<0.0001$ & $<0.0001$ & $<0.0001$ & $<0.0001$ \\
\hline & POR & 0.8189 & 0.9491 & 0.6997 & 0.5120 & 0.1761 & - & 0.6893 & $<0.0001$ & $<0.0001$ & $<0.0001$ & $<0.0001$ & $<0.0001$ & $<0.0001$ \\
\hline & WB & 0.1300 & 0.3042 & 0.0402 & 0.4567 & 0.7145 & 0.0260 & - & $<0.0001$ & $<0.0001$ & $<0.0001$ & $<0.0001$ & $<0.0001$ & $<0.0001$ \\
\hline \multirow[t]{6}{*}{ Landlocked } & SL & 0.0421 & 0.1686 & 0.0551 & 0.1800 & 0.3708 & 0.0926 & 0.0605 & - & $<0.0001$ & $<0.0001$ & $<0.0001$ & $<0.0001$ & $<0.0001$ \\
\hline & QL & 0.0079 & 0.0261 & 0.0047 & 0.0016 & 0.0023 & 0.0096 & 0.0001 & 0.0368 & - & $<0.0001$ & $<0.0001$ & $<0.0001$ & $<0.0001$ \\
\hline & RL & 0.0008 & 0.0052 & 0.0009 & 0.0010 & $<0.0001$ & $<0.0001$ & $<0.0001$ & $<0.0001$ & $<0.0001$ & - & $<0.0001$ & $<0.0001$ & $<0.0001$ \\
\hline & PL & 0.0064 & 0.0724 & 0.0042 & 0.0787 & 0.0054 & 0.0022 & 0.0013 & 0.0007 & $<0.0001$ & 0.0001 & - & $<0.0001$ & $<0.0001$ \\
\hline & $\mathrm{AL}$ & $<0.0001$ & 0.0011 & 0.0008 & 0.0002 & $<0.0001$ & 0.0002 & $<0.0001$ & $<0.0001$ & $<0.0001$ & 0.0004 & 0.0005 & - & $<0.0001$ \\
\hline & $\mathrm{LP}$ & 0.0007 & 0.0199 & 0.0016 & 0.0048 & 0.0004 & 0.0002 & $<0.0001$ & 0.0002 & 0.0006 & 0.0002 & 0.0260 & $<0.0001$ & - \\
\hline
\end{tabular}

0.4321). The low proportion of variation among watersheds likely reflects gene flow among anadromous populations.

Pairwise $F_{\mathrm{ST}}$ (Appendix I) and exact tests of population differentiation (Table 2) based on CR1 haplotype data showed that anadromous populations were generally not significantly differentiated from each other (mean $F_{\mathrm{ST}}=$ 0.038). Landlocked populations, in contrast, were generally significantly differentiated from each other (mean $F_{\mathrm{ST}}$ $=0.460$ ) and occasionally differentiated from anadromous populations (mean $F_{\mathrm{ST}}=0.441$ ), including those directly downstream (mean $\left.F_{\mathrm{ST}}=0.382\right)$. Interestingly, pairwise $F_{\mathrm{ST}}$ and exacts tests showed that the SL population is more closely related to anadromous populations than are other landlocked populations, suggesting either extremely recent landlocking or ongoing gene flow between this population and the downstream anadromous population.

\section{Microsatellites}

For microsatellite data, tests for linkage disequilibrium revealed no evidence of linkage between any loci examined. Tests for departure from HWE revealed a single test to be 
Table 3 Mean number of alleles $\left(N_{\mathrm{a}}\right)$, mean observed heterozygosity $\left(H_{\mathrm{O}}\right)$, and mean expected heterozygosity $\left(H_{\mathrm{E}}\right)$ for microsatellite loci ASA8, ASA9, AA14, AF13, and AF20. Standard deviations for each population or coefficients of variation for each Life-history form are in parentheses

\begin{tabular}{lcrll}
\hline Population & \multicolumn{2}{l}{ Sample size $N_{\mathrm{a}}$} & $H_{\mathrm{O}}$ & \multicolumn{1}{l}{$H_{\mathrm{E}}$} \\
\hline FR (A) & 8 & $6.4(0.872)$ & $0.946(0.033)$ & $0.823(0.050)$ \\
WR (A) & 10 & $6.8(2.775)$ & $0.709(0.262)$ & $0.735(0.220)$ \\
MC (A) & 20 & $10.2(5.541)$ & $0.739(0.205)$ & $0.792(0.179)$ \\
BB (A) & 20 & $9.8(4.147)$ & $0.755(0.167)$ & $0.752(0.202)$ \\
PR (A) & 20 & $8.6(4.336)$ & $0.627(0.195)$ & $0.752(0.193)$ \\
POR (A) & 20 & $9.8(3.962)$ & $0.850(0.158)$ & $0.784(0.157)$ \\
WB (A) & 20 & $9.0(3.464)$ & $0.694(0.199)$ & $0.784(0.198)$ \\
Anadromous & & $8.7(17 \%)$ & $0.760(14 \%)$ & $0.774(4 \%)$ \\
SL (L) & 20 & $6.6(4.159)$ & $0.411(0.220)$ & $0.555(0.342)$ \\
QL (L) & 20 & $4.0(0.707)$ & $0.345(0.345)$ & $0.349(0.179)$ \\
RL (L) & 20 & $4.6(2.302)$ & $0.499(0.263)$ & $0.477(0.185)$ \\
PL (L) & 20 & $4.2(1.789)$ & $0.595(0.208)$ & $0.574(0.108)$ \\
AL (L) & 20 & $3.6(1.140)$ & $0.377(0.322)$ & $0.432(0.229)$ \\
LP (L) & 20 & $4.0(2.000)$ & $0.516(0.247)$ & $0.459(0.202)$ \\
Landlocked & & $4.5(24 \%)$ & $0.457(21 \%)$ & $0.474(17 \%)$ \\
& & & &
\end{tabular}

significant following Bonferroni correction (Appendix II). MICRO-CHECKER suggested five instances of null alleles involving three loci and four populations (ASA9: WB, SL; AA14: QL, AL; and AF13: AL). Locus AA14 and locus AF20 had bimodal allele frequency distributions. Locus ASA9, a tetranucleotide repeat, showed multiple instances of 2-bp allele intervals, as found by Waters et al. (2000) for this locus. These observations are inconsistent with a stepwise mutation model. Several previous microsatellite studies on fishes also rejected the fit of the stepwise mutation model at both deep and shallow phylogenetic levels (Salmonids, Angers \& Bernatchez 1997; Centrarchids, Neff et al. 1999; and Cichlids, van Oppen et al. 2000), possibly because of the high abundance of imperfect microsatellites in fish genomes (Angers \& Bernatchez 1997).

ANOvA revealed anadromous populations to have significantly higher $N_{\mathrm{a}}\left(F_{1,11}=31.533, P<0.001\right)$ and $H_{\mathrm{O}}\left(F_{1,11}\right.$ $=28.802, P<0.001)$ compared to landlocked populations (Table 3). $F_{\mathrm{ST}}$ values (Appendix III) and genotypic tests of homogeneity (Table 2 ) revealed that landlocked populations were significantly differentiated from other landlocked populations (mean $F_{\mathrm{ST}}=0.318$ ) and from anadromous populations (mean $F_{\mathrm{ST}}=0.191$ ), including those directly downstream (mean $\left.F_{\mathrm{ST}}=0.190\right)$. Anadromous populations were not typically significantly differentiated from other anadromous populations (mean $F_{\mathrm{ST}}=0.012$ ). NMDS based on $F_{\mathrm{ST}}$ values (stress $=0.06722, R^{2}=0.98842$ ) indicated a very tight grouping of anadromous populations, a wide scatter of landlocked populations, and intermediate locations of the SL landlocked and the PR anadromous populations (Fig. 3). Analysis with STRUCTURE indicated the presence of $K=8$ natural groups, supporting the results of

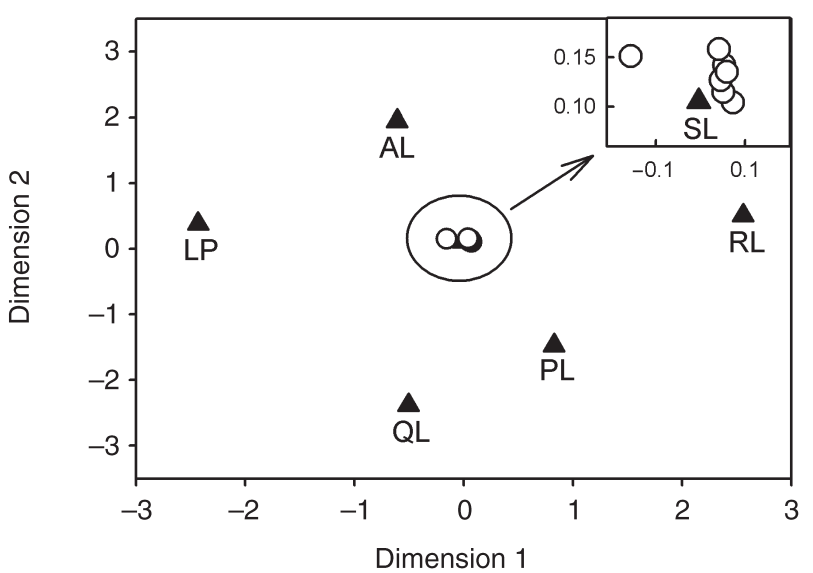

Fig. 3 NMDS plot based on the matrix of pairwise $F_{\mathrm{ST}}$ values from microsatellite data. The inset magnifies the area of the plot containing the anadromous populations and the SL population (landlocked). While anadromous populations $(\bigcirc)$ are clustered together, landlocked populations $(\boldsymbol{\Lambda})$ are spread out. This pattern supports a 'phylogenetic raceme' mode of population divergence.

NMDS. Estimates of gene flow $\left(N_{\mathrm{m}}\right)$ based on private alleles (Appendix III) revealed the highest gene flow to occur between anadromous populations (mean $N_{\mathrm{m}}=3.11$ ), an intermediate level of gene flow to occur between anadromous and landlocked populations (mean $N_{\mathrm{m}}=1.24$ ), and the lowest level of gene flow to occur between landlocked populations (mean $N_{\mathrm{m}}=0.56$ ).

\section{Combined mtDNA and microsatellite analyses}

Mean $F_{\mathrm{ST}}$ values calculated across all markers for within- and between-life-history divergence showed within-life-history divergence for anadromous populations to be the lowest (mean $F_{\mathrm{ST}}=0.015$ ), between-life-history divergence to be intermediate (mean $F_{\mathrm{ST}}=0.228$ ), and within-life-history divergence for landlocked populations to be the highest (mean $F_{\mathrm{ST}}=0.292$ ). ANOvA and post-hoc Tukey tests revealed within-life-history divergence for anadromous populations to be significantly lower than between-life-history divergence $(P=0.01)$ and within-life-history divergence for landlocked populations $(P=0.001)$. In contrast, withinlife-history divergence for landlocked populations was not significantly different from between-life-history divergence $(P=0.557)$, suggesting that landlocked populations are as closely related to anadromous populations as they are to each other. Mantel tests did not indicate significant isolation by distance among anadromous populations for either mtDNA $(P=0.58)$ or microsatellite differentiation $(P=0.22)$.

\section{Phenotypic divergence}

Body size for adult landlocked alewives averaged $97 \mathrm{~mm}$ total length, and body size for adult anadromous alewives 


\begin{tabular}{lllll}
\hline Population & $\begin{array}{l}\text { Gape width } \\
\text { sample size }\end{array}$ & $\begin{array}{l}\text { Gape width } \\
\text { (millimetre) }\end{array}$ & $\begin{array}{l}\text { Gill raker } \\
\text { sample size }\end{array}$ & $\begin{array}{l}\text { Gill raker } \\
\text { spacing (millimetre) }\end{array}$ \\
\hline BL (A) & 17 & $4.52(1.34)$ & 17 & $0.184(0.021)$ \\
DP (A) & 16 & $4.86(0.91)$ & 16 & $0.194(0.024)$ \\
GP (A) & 29 & $4.19(0.95)$ & 23 & $0.183(0.015)$ \\
Anadromous & & $4.52(7.41 \%)$ & & $0.187(3.25 \%)$ \\
PL (L) & 23 & $3.68(0.95)$ & 20 & $0.156(0.017)$ \\
QL (L) & 20 & $3.35(0.61)$ & 17 & $0.148(0.012)$ \\
RL (L) & 20 & $3.81(0.34)$ & 20 & $0.165(0.020)$ \\
Landlocked & & $3.61(6.56 \%)$ & & $0.156(5.44 \%)$ \\
\hline
\end{tabular}

Table 4 Mean trait values for young-of-theyear anadromous and landlocked alewives between $60 \mathrm{~mm}$ and $80 \mathrm{~mm}$ total length. Standard deviations for each population or coefficients of variation indicating amongpopulation variation for each alewife lifehistory form are in parentheses averaged $260 \mathrm{~mm}$ total length. This size difference was significant $\left(F_{1,10.003}=39.772, P<0.0001\right)$. The effect of population (nested within life history) was also significant $\left(F_{10,232}=112.344, P<0.0001\right)$, suggesting substantial body size heterogeneity among populations of each life-history type. This among-population variation in body size was greater for landlocked populations $(\mathrm{CV}=40.1 \%)$ than for anadromous populations $(\mathrm{CV}=3.8 \%)$, suggesting that isolated lakes harbouring landlocked alewives provide more heterogeneous growth opportunities than the common marine environment shared by anadromous populations.

Landlocked alewives differed significantly from anadromous alewives in foraging traits (Table 4). Landlocked alewives had significantly narrower gapes $\left(F_{1,4.055}=12.180\right.$, $P=0.025)$ and smaller inter-raker spacing $\left(F_{1,4.022}=28.176\right.$, $P=0.006)$ than anadromous alewives. Again, the population effect was significant for both gape width $\left(F_{4,119}\right.$ $=2.481, P=0.048)$ and gill raker spacing $\left(F_{4,107}=2.699\right.$, $P=0.035)$, indicating significant heterogeneity among populations of each life-history type.

\section{Divergence time and evolutionary rates}

Divergence time $(t)$ was calculated to be between 180 and 348 generations $\left(\mu_{\mathrm{f}}\right)$ or between 1809 and 3489 generations $\left(\mu_{\mathrm{s}}\right)$. We estimated mean generation time for landlocked alewives using an age-structured population model (Caswell 1989). The result yielded a generation time of $\sim 1.5$ years. These populations were therefore estimated to have become isolated from a common anadromous ancestor between 270 and 522 years ago $\left(\mu_{\mathrm{f}}\right)$ or between 2714 and 5234 years ago $\left(\mu_{\mathrm{s}}\right)$. Using these divergence estimates, we calculated the rate of evolution for gape width and gill raker spacing in haldanes $(h)$. Following the notation proposed by Gingerich (1993) and modified by Hendry \& Kinnison (1999), mean evolutionary rates for gill raker spacing based on fast and slow mutation rates were $h_{\mathrm{p}(2.54)}=0.0071$ and $h_{\mathrm{p}(3.42)}=0.0007$, respectively. Mean evolutionary rates for gape width based on fast and slow mutation rates were $h_{\mathrm{p}(2.54)}=0.0035$ and $h_{\mathrm{p}(3.42)}=0.0004$, respectively (Fig. 4).

\section{Discussion}

Our results indicate that the landlocked alewife populations we examined are independently evolved and that parallel evolution has shaped foraging and life-history traits in these populations. We found no evidence for a phylogenetic split between anadromous and landlocked populations that would indicate a common ancestor for landlocked alewives. The haplotype network based on CR1 sequences did not show a pattern of structuring coincident with lifehistory type (Fig. 2). Our results show that landlocked alewife populations contain a subset of the mitochondrial haplotypes and microsatellite alleles found within anadromous populations and have lower mtDNA diversity (Table 1) and microsatellite diversity (Table 3) than anadromous populations. The NMDS plot of $F_{\mathrm{ST}}$ values for microsatellite data produced a tight grouping of anadromous populations and a wide scatter of landlocked populations (Fig. 3), and the results of STRUCTURE support these groupings.

Combined analysis of mtDNA and microsatellite markers revealed anadromous-landlocked population pairs to be as closely related as landlocked-landlocked population pairs, as would be expected if landlocked populations had evolved independently from downstream anadromous runs. Tests of genetic divergence revealed that landlocked populations are more differentiated from each other than are anadromous populations (Table 2), and estimates of gene flow indicated that landlocked populations are relatively isolated, whereas anadromous populations exchange genes (Appendix III). Interestingly, genetic divergence among anadromous populations did not conform to isolation-by-distance expectations, suggesting that, at the geographical scale of this study $(80 \mathrm{~km}$ between the most distant anadromous runs), distance does not limit gene flow.

Overall, our results suggest a 'phylogenetic raceme' pattern of landlocked alewife population divergence, with anadromous populations forming an ancestral core from which landlocked populations independently diverged. Such a population structure has been found for the 


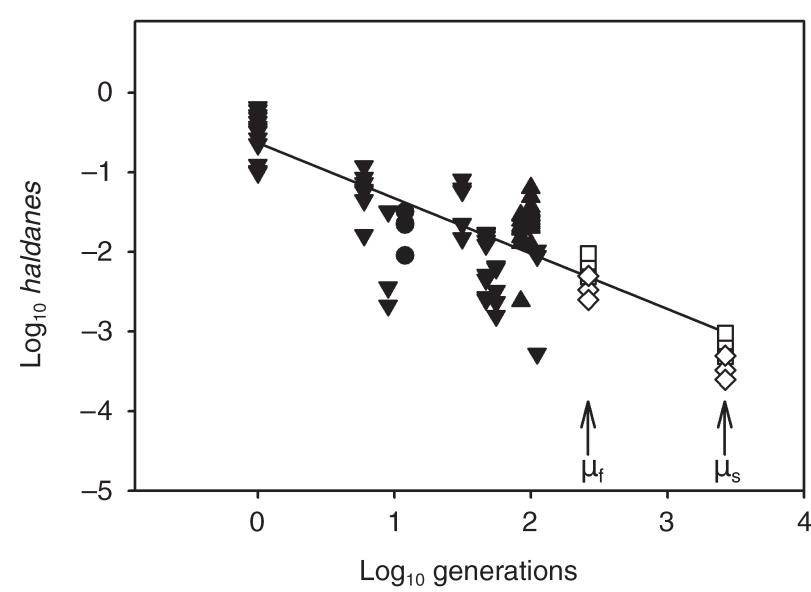

Fig. 4 Evolutionary rates for foraging traits in alewives compared to other species. Alewife rates were calculated using divergence time estimates based on fast $\left(\mu_{\mathrm{f}}=10^{-3}\right)$ and slow $\left(\mu_{\mathrm{s}}=10^{-4}\right)$ microsatellite mutation rates. In alewives, gill raker spacing $(\square)$ evolved faster than gape width $(\diamond)$. Evolutionary rates for foraging traits in birds $(\boldsymbol{\nabla})$, insects $(\boldsymbol{\Delta})$, and fish $(\boldsymbol{\bullet})$ are from Hendry et al. (2007). The least-squares regression line for all rates is shown.

anadromous-freshwater three-spined stickleback complex (Bell 1976; Withler \& McPhail 1985; Bell \& Foster 1994; Taylor \& McPhail 2000; Raeymaekers et al. 2005) and should be common in other systems where small, isolated populations diverge from a relatively unstructured source population. In addition to making predictions about the overall pattern of population differentiation, the phylogenetic raceme model also makes predictions about the identity of alleles within anadromous and freshwater resident populations. Specifically, alleles present in freshwater populations should differ from one population to the next unpredictably, and freshwater populations should contain a subset of the alleles present in anadromous populations (Bell 1976). Our data support these predictions for both mtDNA and microsatellites. We found that the most common haplotype/allele in each landlocked population never had the same identity (with the exception of locus AA14, where a single allele was most common in both anadromous and landlocked populations). Additionally, anadromous populations frequently contained haplotypes/alleles not found in landlocked populations, but landlocked populations rarely contained haplotypes/alleles not found in anadromous populations.

One difficulty with testing independent evolutionary origins under a phylogenetic raceme model of divergence is that the lack of genetic structuring within the ancestral population prevents the formation of the phylogenetically paired, phenotypically differentiated populations that are the conceptual hallmark of parallel evolution. Because ancestral subpopulations exchange genes (and therefore do not diverge) and descendent populations are isolated (and therefore tend to drift apart), a phylogenetic raceme may be incorrectly inferred if a single descendent population rapidly splits into multiple populations that subsequently differentiate.

A single landlocked population could have evolved in freshwater glacial Lake Connecticut (now Long Island Sound) between 15000 and 20000 years ago, and this population may have rapidly dispersed into coastal lakes following glacial retreat about 10000 years ago (Lewis \& Stone 1991; Lewis \& DiGiacomo-Cohen 2000). However, the results of our divergence time estimation make this scenario exceedingly unlikely. First, our maximum divergence estimate places the divergence of landlocked populations around 5000 years ago. This date is considerably more recent than the disappearance of glacial Lake Connecticut and the retreat of the glaciers, which occurred between 10000 and 15000 years ago. Second, observed $G_{\mathrm{ST}}$ for the landlocked alewife populations examined was 0.2811. For comparison, a $G_{\mathrm{ST}}$ of 0.5034 is necessary to produce a divergence time estimate plausible under a scenario where population isolation occurred 10000 years ago. Given how recently landlocked alewife populations in Connecticut are likely to have diverged from their common ancestor, independent evolutionary origins are the most plausible explanation for their observed levels of genetic divergence. Independent evolutionary origins have also been found for freshwater populations of other predominantly anadromous species, including sockeye salmon (Taylor et al. 1996; Taylor 1999), three-spined sticklebacks (Taylor \& McPhail 1999; Raeymaekers et al. 2005), and rainbow smelt (Osmerus mordax, Taylor \& Bentzen 1993).

Post-glacial processes such as isostatic rebound have been proposed to explain the evolution of landlocked populations from anadromous ancestors in other species (Berg 1985; Klepaker 1995; Johnson \& Taylor 2004). However, our divergence time estimates rule out continental uplift as a likely mechanism in this case. So what could be the cause of landlocking for Connecticut alewife populations? Our estimates suggest that landlocked populations are no older than 5000 years and may be as young as 300 years. The older side of this estimate marks a time when the sea-level in Long Island Sound stabilized and the basin assumed its present shape (Lewis \& Stone 1991; Lewis \& DiGiacomoCohen 2000); there does not appear to be evidence of largescale geological activity at this time that would have blocked spawning migrations or isolated inland lakes. The younger side of this estimate marks a time when humans were actively modifying the Connecticut landscape. This was done first by Native Americans and, beginning in the 1630s, by colonial European settlers. Although Native Americans are known to have exploited alewife runs as a resource, there is no evidence that they constructed permanent structures that would have blocked spawning migrations (Cronon 1983). In contrast, one of the first things 
European settlers did upon arriving in Connecticut was to begin building permanent dams to power grain and lumber mills (Cronon 1983). These original dams, or their more modern replacements, are a ubiquitous feature of the Connecticut landscape and undoubtedly disrupted the migrations of many anadromous fishes, including alewives, which migrate up the small streams upon which the earliest dams were constructed. An interesting finding is that, among all landlocked populations examined, the SL population is the least genetically differentiated from anadromous populations (Fig. 3). It is also the most recent to have received a dam - around 1800 vs. around 1700 for the other drainages (S. Gephard, personal communication). Taken together, evidence for independent evolutionary origins coupled with evidence for a recent divergence time makes colonial dam construction a plausible, if not likely, cause of the evolution of landlocked alewife populations in coastal Connecticut lakes. This interpretation suggests that landlocked populations may be geographically native to Connecticut, but that the landlocked phenotype has evolved because of the effects of human activity.

Our examination of foraging traits revealed landlocked alewives to have significantly smaller gill raker spacing and gape width than anadromous alewives (Table 4). In planktivorous fishes, smaller gill raker spacing, which is typically associated with greater numbers of gill rakers, is known to enable the capture of smaller prey items (Drenner et al.1984; Mummert \& Drenner 1986; Gibson 1988; Robinson \& Wilson 1994). Smaller gapes have been found to accompany greater numbers of gill rakers in planktivorous forms of Eurasian perch (Perca fluviatilis, Hjelm et al. 2000) and three-spined sticklebacks (Schluter \& McPhail 1992). Therefore, landlocked alewives appear to have shifted to a morphology better adapted to foraging on smaller zooplankton. Interestingly, nonanadromous kokanee display greater numbers of gill rakers than anadromous sockeye salmon (Wood \& Foote 1996; Foote et al. 1999), nonanadromous 'dwarf' rainbow smelt display more numerous gill rakers than anadromous rainbow smelt (Taylor \& Bentzen 1993), and freshwater limnetic three-spined sticklebacks have more gill rakers than anadromous three-spined sticklebacks (McPhail 1994). These results together suggest that parallel evolution in traits that facilitate the capture of smaller zooplankton may commonly evolve during the transition from anadromy to freshwater residency in planktivorous fishes. In addition, gill raker number is used to distinguish species and subspecies in the genus Alosa (Alexandrino et al. 2006). Therefore, our results may point to ecological differentiation at multiple phylogenetic levels within this genus of planktivores.

Given the recent origin of landlocked alewife populations, it is interesting to compare their rate of morphological evolution to rates of evolution for similar traits in other species. Our results show that evolutionary rates for alewife foraging traits are comparable to rates of contemporary evolution for foraging traits in other species (Fig. 4). Rates of microevolution tend to start fast and decline over time (Kinnison \& Hendry 2001). Therefore, strong selection may have driven an especially high rate of alewife evolution in the period immediately following population isolation.

We speculate that the causes of alewife foraging trait evolution may mirror the causes of Darwin's finch beak evolution. On the island of Daphne Major, size-selective seed predation by Geospiza fortis and its competitor Geospiza magnirostris can reduce the abundance of large seeds, thereby causing a rapid decrease in G. fortis beak size (Grant \& Grant 2006). Similarly, when landlocked alewives first invade a lake, size-selective predation can rapidly eliminate largebodied zooplankton species from the environment (Brooks \& Dodson 1965), perhaps causing rapid decreases in gape size and gill raker spacing. We hypothesize that bursts of evolution in alewife foraging traits may have occurred because of the over-exploitation of large zooplankton by landlocked populations immediately following their isolation in freshwater. Future work will aim to test this hypothesis as a mechanism to explain the pattern of rapid parallel evolution uncovered here.

\section{Acknowledgements}

Thanks to S. Gephard and D. Ellis for assisting with anadromous alewife sampling, and to R. Doud, C. Dalton, and E. O'Donnell for assisting with landlocked alewife sampling. C. Mariani helped with sequencing and genotyping, and K. Griswold provided primers for microsatellite loci ASA2, ASA8, and ASA9. T. Shao made the alewife illustration in Fig. 1. A. P. Hendry, D. K. Skelly, S. C. Stearns, C. E. Burns, M. A. Bell, E. B. Taylor and three anonymous reviewers provided helpful comments on the manuscript. This work was funded by an Environmental Protection Agency Science to Achieve Results (EPA STAR) Graduate Fellowship to E.P.P. and a Connecticut Institute of Water Resources (CT IWR) grant to D.M.P. This publication is not officially endorsed by the US EPA and may not reflect the views of the agency.

\section{References}

Alexandrino P, Faria R, Linhares D et al. (2006) Interspecific differentiation and intraspecific substructure in two closely related clupeids with extensive hybridization, Alosa alosa and Alosa fallax. Journal of Fish Biology, 69 (Suppl. B), 242-259.

Angers B, Bernatchez L (1997) Complex evolution of a salmonid microsatellite locus and its consequences in inferring allelic divergence from size information. Molecular Biology and Evolution, 14, 230-238.

Avise JC (2000) Phylogeography: The History and Formation of Species. Harvard University Press, Cambridge, Massachusetts.

Barton NH, Slatkin M (1986) A quasi-equilibrium theory of the distribution of rare alleles in a subdivided population. Heredity, 56, 409-415.

Belkhir K, Borsa P, Chikhi L, Raufaste N, Bonhomme F (1996-2004) genetix 4.05, Logiciel Sous Windows TM Pour la Génétique des Populations. Laboratoire Génome, Populations, Interactions, 
CNRS UMR 5000, Université de Montpellier II, Montpellier, France.

Bell MA (1976) Evolution of phenotypic diversity in the Gasterosteus aculeatus superspecies on the Pacific coast of North America. Systematic Zoology, 25, 211-227.

Bell MA, Foster SA (1994) Introduction to the evolutionary biology of the threespine stickleback. In: The Evolutionary Biology of the Threespine Stickleback (eds Bell MA, Foster SA), pp. 1-26. Oxford University Press, Oxford, UK.

Berg OK (1985) The formation of non-anadromous populations of Atlantic salmon, Salmo salar L., in Europe. Journal of Fish Biology, 27, 805-815.

Bernatchez L (2004) Ecological theory of adaptive radiation: an empirical assessment from coregonine fishes (Salmoniformes). In: Evolution Illuminated: Salmon and Their Relatives (eds Hendry AP, Stearns SC), pp. 175-207. Oxford Univerity Press, Oxford, UK.

Bernatchez L, Chouinard A, Lu G (1999) Integrating molecular genetics and ecology in studies of adaptive radiation: whitefish, Coregonus sp., as a case study. Biological Journal of the Linnean Society, 68, 173-194.

Brooks JL, Dodson SI (1965) Predation, body size, and composition of plankton. Science, 150, 28-35.

Caccone A, Amato G, Gratry OC, Behler J, Powell JR (1999) A molecular phylogeny of four endangered Madagascar tortoises based on mtDNA sequences. Molecular Phylogenetics and Evolution, 12, 1-9.

Caswell H (1989) Matrix Population Models. Sinauer \& Associates, Sunderland, Massachusetts.

Clement M, Posada D, Crandall KA (2000) TCs: a computer program to estimate gene geneaologies. Molecular Ecology, 9, 1657-1659.

Crandall KA, Templeton AR (1993) Empirical tests of some predictions from coalescent theory with applications to intraspecific phylogeny reconstruction. Genetics, 134, 959-969.

Cronon W (1983) Changes in the Land: Indians, Colonists, and the Ecology of New England. Hill and Wang, New York.

Crow JF, Kimura M (1970) An Introduction to Population Genetics Theory. Harper \& Row, New York.

Davis JP (2004) Analysis of anadromous alewife (Alosa pseudoharengus) and blueback herring (A. aestivalis) runs in Connecticut. Master's Thesis, University of Connecticut, Storrs, Connecticut.

Drenner RW, Mummert JR, DeNoyelles FJ, Kettle D (1984) Selective particle ingestion by a filter-feeding fish and its impact on phytoplankton community structure. Limnology and Oceanography, 29, 941-948.

Ellegren H (2000) Microsatellite mutations in the germline: implications for evolutionary inference. Trends in Genetics, 16, 551-558.

Endler JA (1986) Natural Selection in the Wild. Princeton University Press, Princeton, New Jersey.

Excoffier L, Smouse P, Quattro J (1992) Analysis of molecular variance inferred from metric distances among DNA haplotypes: applications to human mitochondrial DNA restriction data. Genetics, 131, 479-491.

Faria R, Wallner B, Weiss S, Alexandrino P (2004) Isolation and characterization of eight dinucleotide microsatellite loci from two closely related clupeid species (Alosa alosa and A. fallax). Molecular Ecology Notes, 4, 586-588.

Faria R, Weiss S, Alexandrino P (2006) A molecular phylogenetic perspective on the evolutionary history of Alosa spp. (Clupeidae). Molecular Phylogenetics and Evolution, 40, 298-304.
Foote CJ, Moore K, Stenberg K et al. (1999) Genetic differentiation in gill raker number and length in sympatric anadromous and nonanadromous morphs of sockeye salmon, Oncorhynchus nerka. Environmental Biology of Fishes, 54, 263-274.

Friedland KD, Ahrenholz DW, Smith JW, Manning M, Ryan J (2006) Sieving functional morphology of the gill raker feeding apparatus of Atlantic menhaden. Journal of Experimental Zoology Part A-Comparative Experimental Biology, 305A, 974-985.

Gibson RN (1988) Development, morphometry, and particle retention capability of the gill rakers in the herring, Clupea harengus L. Journal of Fish Biology, 32, 949-962.

Gingerich PD (1993) Quantification and comparison of evolutionary rates. American Journal of Science, 293A, 453-478.

Goudet J, Raymond M, deMeeus T, Rousset F (1996) Testing differentiation in diploid populations. Genetics, 144, 1933-1940.

Graham JJ (1956) Observations on the alewife, Pomolobus Pseudoharengus (Wilson), in fresh water. University of Toronto Biological Series No. 62, Publications of the Ontario Fisheries Research Laboratory, 74, $43 \mathrm{p}$.

Grant PR, Grant BR (2006) Evolution of character displacement in Darwin's finches. Science, 313, 224-226.

Harman WN, Albright MF (2002) Trophic changes in Otsego Lake, NY following the introduction of the alewife (Alosa psuedoharengus). Lake and Reservoir Management, 18, 215-226.

Harvey PH, Pagel MD (1991) The Comparative Method in Evolutionary Biology. Oxford University Press, Oxford, UK.

Hendry AP, Bohlin T, Jonsson B, Berg OK (2004) To sea or not to sea? Anadromy versus non-anadromy in Salmonids. In: Evolution Illuminated Salmon and Their Relatives (eds Hendry AP, Stearns SC). Oxford University Press, Oxford, UK.

Hendry AP, Kinnison MT (1999) Perspective: the pace of modern life: measuring rates of contemporary microevolution. Evolution, 53, 1637-1653.

Hendry AP, Farrugia TJ, Kinnison MT (2007) Human influences on rates of phenotypic change in wild animal populations. Molecular Ecology. doi: 10.1111/j.1365-294X.2007.03428.x.

Hjelm J, Persson L, Christensen B (2000) Growth, morphological variation and ontogenetic niche shifts in perch (Perca fluviatilis) in relation to resource availability. Oecologia, 122, 190-199.

Hutchinson BP (1971) Effect of fish predation on the zooplankton of ten Adirondack lakes, with particular reference to alewife, Alosa pseudoharengus. Transactions of the American Fisheries Society, 100, 325-335.

Ihssen PE, Martin GW, Rodgers DW (1992) Allozyme variation of Great Lakes alewife, Alosa pseudoharengus: genetic differentiation and affinities of a recent invader. Canadian Journal of Fisheries and Aquatic Sciences, 49, 1770-1777.

Jacobs RP, O'Donnell EB (2002) A Fisheries Guide to Lakes and Ponds of Connecticut Including the Connecticut River and Its Coves. Connecticut Department of Environmental Protection, Hartford, Connecticut.

Janssen J (1976) Feeding modes and prey size selection in the alewife (Alosa pseudoharengus). Journal of the Fisheries Research Board of Canada, 33, 1972-1975.

Jin L, Chakraborty R (1995) Population structure, stepwise mutations, and heterozygote deficiency and their implications in DNA forensics. Heredity, 74, 274-285.

Johnson LS, Taylor EB (2004) The distribution of divergent mitochondrial DNA lineages of threespine stickleback (Gasterosteus aculeatus) in the northeastern Pacific Basin: post-glacial dispersal and lake accessibility. Journal of Biogeography, 31, 1073-1083. 
Kinnison MT, Hendry AP (2001) The pace of modern life II: from rates of contemporary microevolution to pattern and process. Genetica, 112, 145-164.

Kissil GW (1974) Spawning of anadromous alewife, Alosa pseudoharengus, in Bride Lake, Connecticut. Transactions of the American Fisheries Society, 103, 312-317.

Klepaker T (1995) Postglacial evolution in lateral plate morphs in Norwegian fresh-water populations of threespine stickleback (Gasterosteus aculeatus). Canadian Journal of Zoology, 73, 898-906.

Kocher TD, Thomas WK, Meyer A et al. (1989) Dynamics of mitochondrial DNA evolution in mammals: amplification and sequencing with conserved primers. Proceedings of the National Academy of Sciences, USA, 86, 6196-6200.

Kuhn KL (2004) Patterns of microsatellite and mitochondrial DNA variation among anadromous and freshwater alewife (Alosa pseudoharengus) poulations. Master's Thesis, University of Maine, Orono, Maine.

Lazzaro X (1987) A review of planktivorous fishes: their evolution, feeding behaviours, selectivities, and impacts. Hydrobiologia, 146, 97-167.

Lee WJ, Conroy J, Howell WH, Kocher TD (1995) Structure and evolution of teleost mitochondrial control regions. Journal of Molecular Evolution, 41, 54-66.

Lewis RS, DiGiacomo-Cohen M (2000) A review of the geologic framework of the Long Island Sound basin, with some observations relating to postglacial sedimentation. Journal of Coastal Research, 16, 522-532.

Lewis RS, Stone JR (1991) Late Quaternary stratigraphy and depositional history of the Long Island Sound Basin: Connecticut and New York. Journal of Coastal Research Special Issue, 11, 1-23.

Lindsey CC (1981) Stocks are chamelons: plasticity in gill rakers of Coregonid fishes. Canadian Journal of Fisheries and Aquatic Sciences, 38, 1497-1506.

Losos JB, Jackman TR, Larson A, de Queiroz K, Rodriguez-Schettino L (1998) Contingency and determinism in replicated adaptive radiations of island lizards. Science, 279, 2115-2118.

Lu G, Bernatchez L (1999) Correlated trophic specialization and genetic divergence in sympatric lake whitefish ecotypes (Coregonus clupeaformis): support for the ecological speciation hypothesis. Evolution, 53, 1491-1505.

MacNeill DB, Brandt SB (1990) Ontogenic shifts in gill-raker morphology and predicted prey capture efficiency of the alewife, Alosa pseudoharengus. Copeia, 1990, 164-171.

McKinnon JS, Rundle HD (2002) Speciation in nature: the threespine stickleback model systems. Trends in Ecology \& Evolution, 17, 480-488.

McKinnon JS, Mori S, Blackman BK et al. (2004) Evidence for ecology's role in speciation. Nature, 429, 294-298.

McPhail JD (1994) Speciation and the evolution of reproductive isolation in the sticklebacks (Gasterosteus) of south-wetsern British Columbia. In: The Eolutonary Biology of the Threespine Stickleback (eds Bell MA, Foster SA). Oxford University Press, Oxford, UK.

Mills EL, Leach JH, Carlton JT, Secor CL (1993) Exotic species in the Great-Lakes - a history of biotic crises and anthropogenic introductions. Journal of Great Lakes Research, 19, 1-54.

Mummert JR, Drenner RW (1986) Effect of fish size on the filtering efficiency and selective particle ingestion of a filter-feeding Clupeid. Transactions of the American Fisheries Society, 115, 522528.

Neff BD, Fu P, Gross MR (1999) Microsatellite evolution in sunfish
(Centrarchidae). Canadian Journal of Fisheries and Aquatic Sciences, 56, 1198-1205.

Nei M, Chesser RK (1983) Estimation of fixation indices and gene diversities. Annals of Human Genetics, 47, 253-259.

van Oosterhout C, Hutchinson WF, Wills DPM, Shipley P (2004) MICRO-CHECKER: software for identifying and correcting genotyping errors in microsatellite data. Molecular Ecology Notes, 4, 535-538.

van Oppen MJH, Rico C, Turner GF, Hewitt GM (2000) Extensive homoplasy, nonstepwise mutations, and shared ancestral polymorphism at a complex microsatellite locus in Lake Malawi cichlids. Molecular Biology and Evolution, 17, 489-498.

Ostbye K, Amundsen PA, Bernatchez L et al. (2006) Parallel evolution of ecomorphological traits in the European whitefish Coregonus lavaretus (L.) species complex during postglacial times. Molecular Ecology, 15, 3983-4001.

Pääbo S (1990) Amplifying ancient DNA. In: PCR Protocols, a Guide to Methods and Applications (eds Innis MA, Gelfand DH, Sninsky DH, White TJ), pp. 159-166. Academic Press, New York.

Palkovacs EP (2007) Feedbacks between ecology and evolution: linking the causes and consequences of functional biodiversity. PhD Thesis, Yale University, New Haven, Connecticut.

Palumbi S, Martin A, Romano S et al. (1991) The Simple Fool's Guide to PCR, Version 2.0. University of Hawaii, Honolulu, Hawaii.

Phillips C, Schluntz E, Bender J (1987) E. Landlocked Alewife (Alosa pseudoharengus) Research and Management in Connecticut Lakes and Ponds. Connecticut Department of Environmental Protection, Hartford, Connecticut.

Posada D, Crandall KA (2001) Intraspecific gene geneaologies: trees grafting into networks. Trends in Ecology \& Evolution, 16, 37-45.

Pritchard JK, Stephens M, Donnelly P (2000) Inference of population structure using multilocus genotype data. Genetics, 155, 945-959.

Raeymaekers JAM, Maes GE, Audenaert E, Volckaert FAM (2005) Detecting Holocene divergence in the anadromous-freshwater three-spined stickleback (Gasterosteus aculeatus) system. Molecular Ecology, 14, 1001-1014.

Raymond M, Rousset F (1995a) An exact test for population differentiation. Evolution, 49, 1280-1283.

Raymond M, Rousset F (1995b) GENEPOP (version 1.2): population genetics software for exact tests and ecumenicism. Journal of Heredity, 86, 248-249.

Reznick DN, Ghalambor CK (2001) The population ecology of contemporary adaptations: what empirical studies reveal about the conditions that promote adaptive evolution. Genetica, 112, 183-198.

Richkus WA (1975) Migratory behavior and growth of juvenile anadromous alewives, Alosa pseudoharengus, in a Rhode Island drainage. Transactions of the American Fisheries Society, 104, 483493.

Robinson BW, Wilson DS (1994) Character release and displacement in fishes: a neglected literature. American Naturalist, 144, 596-627.

Rundle HD, Nagel L, Boughman JW, Schluter D (2000) Natural selection and parallel speciation in sympatric sticklebacks. Science, 287, 306-308.

Schluter D, McPhail JD (1992) Ecological character displacement and speciation in sticklebacks. American Naturalist, 140, 85-108.

Schluter D, Clifford EA, Nemethy M, McKinnon JS (2004) Parallel evolution and inheritance of quantitative traits. American Naturalist, 163, 809-822. 
Schneider S, Roessli D, Excoffier L (2000) ARLEQUIN: A Software for Population Genetics Data Analysis. Ver 2.000. Genetics and Biometry Laboratory, Department of Anthropology, University of Geneva, Geneva, Switzerland.

Scott WB, Crossman EJ (1973) Freshwater Fishes of Canada. Fisheries Research Board of Canada, Ottawa, Canada.

Slatkin M (1985) Rare alleles as indicators of gene flow. Evolution, 39, 53-65.

Taylor EB (1999) Species pairs of north temperate freshwater fishes: evolution, taxonomy, and conservation. Reviews in Fish Biology and Fisheries, 9, 299-324.

Taylor EB, Bentzen P (1993) Evidence for multiple origins and sympatric divergence of trophic ecotypes of smelt (Osmerus) in northeastern North America. Evolution, 47, 813-832.

Taylor EB, McPhail JD (1999) Evolutionary history of an adaptive radiation in species pairs of threespine sticklebacks (Gasterosteus): insights from mitochondrial DNA. Biological Journal of the Linnean Society, 66, 271-291.

Taylor EB, McPhail JD (2000) Historical contingency and ecological determinism interact to prime speciation in sticklebacks, Gasterosteus. Proceedings of the Royal Society B: Biological Sciences, 267, 2375-2384.

Taylor EB, Foote CJ, Wood CC (1996) Molecular genetic evidence for parallel life-history evolution within a Pacific salmon (sockeye salmon and kokanee, Oncorhynchus nerka). Evolution, 50, 401-416.

Thompson JD, Higgins DG, Gibson TJ (1994) CLUSTAL w: improving the sensitivity of progressive multiple sequence alignment through sequence weighting, positions specific gap penalties and weight matrix choice. Nucleic Acids Research, 2, 4673-4680.

Warshaw SJ (1972) Effects of alewives (Alosa pseudoharengus) on zooplankton of Lake Wononskopomuc, Connecticut. Limnology and Oceanography, 17, 816-825.

Waters JM, Epifanio JM, Gunter T, Brown BL (2000) Homing behaviour facilitates subtle genetic differentiation among river populations of Alosa sapidissima: microsatellites and mtDNA. Journal of Fish Biology, 56, 622-636.

Weir BS, Cockerham CC (1984) Estimating F-statistics for the analysis of population structure. Evolution, 38, 1358-1370.
Wells L (1970) Effects of alewife predation on zooplankton populations in Lake Michigan. Limnology and Oceanography, 15, 556-\&.

Withler RE, McPhail JD (1985) Genetic variability in freshwater and anadromous sticklebacks (Gasterosteus aculeatus) of southern British Columbia. Canadian Journal of Zoology, 63, 528-533.

Wood CC, Foote CJ (1990) Genetic differences in the early development and growth of sympatric sockeye salmon and kokanee (Oncorhynchus nerka), and their hybrids. Canadian Journal of Fisheries and Aquatic Sciences, 47, 2250-2260.

Wood CC, Foote CJ (1996) Evidence for sympatric genetic divergence of anadromous and nonanadromous morphs of sockeye salmon (Oncorhynchus nerka). Evolution, 50, 1265-1279.

Yako LA, Mather ME, Juanes F (2002) Mechanisms for migration of anadromous herring: an ecological basis for effective conservation. Ecological Applications, 12, 521-534.

This study was conducted as part of Eric Palkovacs' Ph.D. dissertation focused on understanding the evolutionary causes and ecological consequences of phenotypic divergence between anadromous and landlocked alewife populations. Currently a Postdoctoral Researcher at the University of Maine-Orono, Eric is interested in integrating molecular, phenotypic, and ecological information to understand how interactions between ecology and evolution shape the evolution of phenotypic diversity and the structure of ecological communities. Kirstin Dion, a Research Assistant in the YIBS Molecular Systematics and Conservation Genetics Laboratory, is interested in the application of genetic and genomic approaches to questions related to population biology and conservation. David Post, an Associate Professor of Ecology and Evolutionary Biology, is an aquatic ecologist interested in how intraspecific variation mediates community structure, complex trophic interactions, and ecosystem function. Adalgisa Caccone, the Director of the YIBS Molecular Systematics and Conservation Genetics Laboratory, works on a wide diversity of organisms and questions related to island biogeography, population genetics, and conservation genetics. 
596 E. P. PALKOVACS ET AL.

\section{Appendix I}

Mitochondrial DNA $F_{\mathrm{ST}}$ values calculated using ARLEQUIN 2.0 (Schneider et al. 2000)

\begin{tabular}{|c|c|c|c|c|c|c|c|c|c|c|c|c|c|c|c|c|c|}
\hline & & \multicolumn{9}{|c|}{ Anadromous } & \multicolumn{7}{|c|}{ Landlocked } \\
\hline & & FR & WR & $\mathrm{MC}$ & $\mathrm{BB}$ & GP & DP & PR & POR & WB & SL & QL & RL & PL & $\mathrm{AL}$ & $\mathrm{AP}$ & LP \\
\hline \multirow[t]{9}{*}{ Anadromous } & FR & & & & & & & & & & & & & & & & \\
\hline & WR & 0.002 & & & & & & & & & & & & & & & \\
\hline & $\mathrm{MC}$ & -0.019 & 0.041 & & & & & & & & & & & & & & \\
\hline & $\mathrm{BB}$ & 0.055 & -0.083 & 0.080 & & & & & & & & & & & & & \\
\hline & GP & 0.026 & 0.087 & 0.068 & 0.101 & & & & & & & & & & & & \\
\hline & DP & 0.118 & -0.038 & 0.129 & -0.093 & 0.129 & & & & & & & & & & & \\
\hline & PR & 0.036 & -0.033 & 0.081 & -0.068 & 0.105 & -0.055 & & & & & & & & & & \\
\hline & POR & -0.070 & 0.020 & 0.008 & 0.055 & 0.065 & 0.116 & 0.037 & & & & & & & & & \\
\hline & WB & 0.083 & 0.031 & 0.109 & 0.015 & 0.126 & 0.029 & -0.020 & 0.094 & & & & & & & & \\
\hline \multirow[t]{7}{*}{ Landlocked } & SL & 0.159 & 0.071 & 0.179 & 0.123 & 0.257 & 0.208 & 0.101 & 0.152 & 0.218 & & & & & & & \\
\hline & QL & 0.489 & 0.340 & 0.489 & 0.456 & 0.559 & 0.546 & 0.503 & 0.502 & 0.649 & 0.292 & & & & & & \\
\hline & RL & 0.589 & 0.372 & 0.573 & 0.378 & 0.580 & 0.392 & 0.486 & 0.581 & 0.624 & 0.627 & 0.729 & & & & & \\
\hline & PL & 0.456 & 0.221 & 0.466 & 0.228 & 0.471 & 0.252 & 0.344 & 0.464 & 0.493 & 0.475 & 0.577 & 0.118 & & & & \\
\hline & $\mathrm{AL}$ & 0.531 & 0.391 & 0.552 & 0.447 & 0.552 & 0.490 & 0.551 & 0.537 & 0.664 & 0.655 & 0.713 & 0.482 & 0.343 & & & \\
\hline & $\mathrm{AP}$ & 0.688 & 0.541 & 0.694 & 0.599 & 0.692 & 0.635 & 0.688 & 0.692 & 0.785 & 0.768 & 0.805 & 0.565 & 0.427 & 0.044 & & \\
\hline & LP & 0.428 & 0.194 & 0.444 & 0.181 & 0.430 & 0.194 & 0.293 & 0.435 & 0.448 & 0.448 & 0.590 & 0.142 & -0.030 & 0.393 & 0.488 & \\
\hline
\end{tabular}

\section{Appendix II}

Sample sizes $(N)$, unbiased expected heterozygosity $\left(H_{\mathrm{E}}\right)$, observed heterozygosity $\left(H_{\mathrm{O}}\right)$, number of alleles $\left(N_{\mathrm{a}}\right)$, inbreeding coefficient for individuals $\left(F_{\mathrm{IS}}\right)$, and the probability of departure from Hardy-Weinberg equilibrium $(P)$ for anadromous $(\mathrm{A})$ and landlocked (L) populations sampled. The range of allele sizes (in base pairs) is given below each locus name

\begin{tabular}{|c|c|c|c|c|c|c|c|c|c|c|c|c|c|c|}
\hline Locus & & FR (A) & WR (A) & $\mathrm{MC}(\mathrm{A})$ & BB (A) & PR (A) & POR (A) & WB (A) & SL (L) & QL (L) & RL (L) & PL (L) & AL (L) & $\mathrm{LP}(\mathrm{L})$ \\
\hline ASA8 & $N$ & 8 & 10 & 20 & 19 & 20 & 20 & 19 & 20 & 20 & 20 & 20 & 20 & 20 \\
\hline \multirow[t]{5}{*}{ 114-134 } & $H_{\mathrm{E}}$ & 0.625 & 0.358 & 0.485 & 0.399 & 0.422 & 0.524 & 0.437 & 0.050 & 0.189 & 0.412 & 0.508 & 0.142 & na \\
\hline & $H_{\mathrm{O}}^{\mathrm{E}}$ & 0.875 & 0.400 & 0.500 & 0.474 & 0.350 & 0.600 & 0.421 & 0.050 & 0.150 & 0.450 & 0.400 & 0.150 & na \\
\hline & $N_{\mathrm{a}}$ & 3 & 3 & 5 & 4 & 3 & 5 & 4 & 2 & 3 & 3 & 2 & 2 & 1 \\
\hline & $F_{\text {IS }}^{\mathrm{a}}$ & -0.441 & -0.125 & -0.033 & -0.191 & 0.174 & -0.149 & 0.037 & 0.000 & 0.208 & -0.096 & 0.217 & -0.056 & na \\
\hline & $P$ & 0.326 & 1.000 & 1.000 & 1.000 & 0.656 & 0.833 & 0.324 & na & 0.150 & 0.772 & 0.392 & 1.000 & na \\
\hline ASA9 & $N$ & 8 & 9 & 20 & 20 & 20 & 20 & 20 & 15 & 20 & 19 & 20 & 20 & 20 \\
\hline \multirow[t]{5}{*}{$144-300$} & $H_{\mathrm{E}}$ & 0.884 & 0.758 & 0.857 & 0.791 & 0.821 & 0.769 & 0.809 & 0.908 & 0.316 & 0.545 & 0.555 & 0.458 & 0.664 \\
\hline & $H_{\mathrm{O}}$ & 1.000 & 0.444 & 0.650 & 0.750 & 0.650 & 0.800 & 0.550 & 0.533 & 0.300 & 0.526 & 0.550 & 0.450 & 0.800 \\
\hline & $N_{\mathrm{a}}$ & 8 & 5 & 8 & 8 & 9 & 7 & 7 & 13 & 5 & 4 & 3 & 4 & 6 \\
\hline & $F_{\mathrm{IS}}$ & -0.143 & 0.429 & 0.246 & 0.053 & 0.212 & -0.041 & 0.326 & 0.421 & 0.050 & 0.035 & 0.010 & 0.017 & -0.211 \\
\hline & $P$ & 0.499 & 0.035 & 0.141 & 0.681 & 0.044 & 0.474 & 0.005 & 0.005 & 0.333 & 0.021 & 0.710 & 0.116 & 0.234 \\
\hline AA14 & $N$ & 7 & 10 & 20 & 20 & 20 & 20 & 19 & 19 & 19 & 20 & 19 & 20 & 20 \\
\hline \multirow[t]{5}{*}{ 114-180 } & $H_{\mathrm{E}}$ & 0.846 & 0.784 & 0.881 & 0.798 & 0.752 & 0.817 & 0.876 & 0.423 & 0.245 & 0.436 & 0.576 & 0.276 & 0.189 \\
\hline & $H_{\mathrm{O}}$ & 1.000 & 0.900 & 0.900 & 0.800 & 0.600 & 0.900 & 0.789 & 0.421 & 0.105 & 0.450 & 0.579 & 0.100 & 0.200 \\
\hline & $N_{\mathrm{a}}$ & 7 & 8 & 12 & 12 & 9 & 12 & 12 & 4 & 4 & 7 & 6 & 4 & 3 \\
\hline & $F_{\mathrm{IS}}^{\mathrm{a}}$ & -0.200 & -0.157 & -0.022 & -0.003 & 0.206 & -0.105 & 0.102 & 0.004 & 0.577 & -0.033 & -0.005 & 0.643 & -0.063 \\
\hline & $P$ & 1.000 & 0.995 & 0.637 & 0.649 & 0.044 & 0.797 & 0.125 & 1.000 & 0.005 & 0.607 & 0.795 & 0.007 & 1.000 \\
\hline AF13 & $N$ & 7 & 10 & 14 & 20 & 11 & 20 & 16 & 17 & 18 & 18 & 20 & 14 & 16 \\
\hline \multirow[t]{5}{*}{ 158-196 } & $H_{\mathrm{E}}$ & 0.901 & 0.847 & 0.799 & 0.881 & 0.861 & 0.896 & 0.903 & 0.818 & 0.344 & 0.246 & 0.477 & 0.561 & 0.541 \\
\hline & $H_{\mathrm{O}}$ & 1.000 & 0.900 & 0.643 & 0.900 & 0.636 & 1.000 & 0.813 & 0.632 & 0.222 & 0.167 & 0.500 & 0.286 & 0.563 \\
\hline & $N_{\mathrm{a}}$ & 7 & 8 & 7 & 10 & 7 & 10 & 10 & 7 & 4 & 2 & 4 & 3 & 5 \\
\hline & $F_{\mathrm{IS}}$ & -0.120 & -0.066 & 0.201 & -0.224 & 0.271 & -0.119 & 0.103 & 0.141 & 0.362 & 0.329 & -0.050 & 0.500 & -0.043 \\
\hline & $P$ & 1.000 & 0.573 & 0.202 & 0.413 & 0.056 & 0.760 & 0.203 & 0.005 & 0.008 & 0.270 & 1.000 & 0.017 & 0.904 \\
\hline AF20 & $N$ & 7 & 10 & 20 & 20 & 20 & 20 & 19 & 19 & 19 & 20 & 19 & 20 & 20 \\
\hline \multirow[t]{5}{*}{$184-238$} & $H_{\mathrm{E}}$ & 0.857 & 0.926 & 0.938 & 0.890 & 0.907 & 0.916 & 0.895 & 0.575 & 0.650 & 0.748 & 0.754 & 0.723 & 0.444 \\
\hline & $H_{\mathrm{O}}$ & 0.857 & 0.900 & 1.000 & 0.850 & 0.900 & 0.950 & 0.895 & 0.421 & 0.947 & 0.900 & 0.947 & 0.900 & 0.500 \\
\hline & $N_{\mathrm{a}}$ & 7 & 10 & 19 & 15 & 15 & 15 & 12 & 7 & 4 & 7 & 6 & 5 & 5 \\
\hline & $F_{\text {IS }}^{\mathrm{a}}$ & 0.000 & 0.030 & -0.069 & 0.046 & 0.007 & -0.039 & 0.000 & 0.273 & -0.476 & -0.211 & -0.266 & -0.253 & -0.131 \\
\hline & $P$ & 0.564 & 0.754 & 0.437 & 0.342 & 0.762 & 0.817 & 0.775 & 0.216 & 0.031 & 0.058 & $<0.001$ & 0.256 & 0.568 \\
\hline
\end{tabular}


EVOLUTION OF LANDLOCKED ALEWIVES 597

\section{Appendix III}

Microsatellite $N_{\mathrm{m}}$ values (above diagonal) calculated according to the private allele method of Slatkin (1985) and Barton \& Slatkin (1986), and microsatellite $F_{\mathrm{ST}}$ values (below diagonal) calculated following Weir \& Cockerham (1984).

\begin{tabular}{|c|c|c|c|c|c|c|c|c|c|c|c|c|c|c|}
\hline & & \multicolumn{7}{|c|}{ Anadromous } & \multicolumn{6}{|c|}{ Landlocked } \\
\hline & & FR & WR & $\mathrm{MC}$ & $\mathrm{BB}$ & PR & POR & WB & SL & QL & RL & PL & $\mathrm{AL}$ & $\mathrm{LP}$ \\
\hline \multirow[t]{7}{*}{ Anadromous } & FR & & 1.669 & 3.528 & 4.624 & 1.813 & 3.088 & 2.611 & 0.985 & 0.633 & 0.942 & 0.534 & 0.693 & 0.804 \\
\hline & WR & 0.015 & & 1.557 & 1.992 & 1.081 & 1.476 & 1.335 & 1.005 & 1.096 & 0.547 & 0.590 & 0.764 & 0.878 \\
\hline & $\mathrm{MC}$ & 0.005 & 0.031 & & 4.581 & 3.891 & 4.074 & 4.158 & 1.664 & 1.674 & 1.570 & 1.397 & 1.361 & 2.081 \\
\hline & $\mathrm{BB}$ & 0.008 & 0.009 & 0.003 & & 3.048 & 4.665 & 4.490 & 1.602 & 1.821 & 1.800 & 1.454 & 1.385 & 2.028 \\
\hline & $\mathrm{PR}$ & 0.022 & 0.037 & 0.021 & 0.019 & & 3.428 & 2.794 & 1.064 & 0.687 & 0.539 & 0.634 & 0.857 & 1.059 \\
\hline & POR & 0.015 & 0.017 & 0.001 & -0.004 & 0.017 & & 5.413 & 1.339 & 1.645 & 1.347 & 1.299 & 1.574 & 2.864 \\
\hline & WB & 0.004 & 0.023 & 0.007 & 0.002 & 0.004 & -0.003 & & 1.317 & 1.576 & 1.116 & 1.404 & 1.231 & 1.156 \\
\hline \multirow[t]{6}{*}{ Landlocked } & SL & 0.105 & 0.097 & 0.120 & 0.096 & 0.115 & 0.108 & 0.107 & & 0.680 & 0.768 & 0.430 & 0.649 & 0.962 \\
\hline & QL & 0.277 & 0.240 & 0.245 & 0.238 & 0.267 & 0.235 & 0.242 & 0.280 & & 0.941 & 0.923 & 0.371 & 0.573 \\
\hline & RL & 0.202 & 0.269 & 0.231 & 0.218 & 0.261 & 0.210 & 0.230 & 0301 & 0.409 & & 0.205 & 0.396 & 0.315 \\
\hline & PL & 0.166 & 0.191 & 0.169 & 0.175 & 0.174 & 0.160 & 0.161 & 0.285 & 0.182 & 0.292 & & 0.369 & 0.348 \\
\hline & $\mathrm{AL}$ & 0.192 & 0.152 & 0.165 & 0.129 & 0.183 & 0.152 & 0.172 & 0.235 & 0.388 & 0.371 & 0.323 & & 0.476 \\
\hline & $\mathrm{LP}$ & 0.238 & 0.240 & 0.179 & 0.197 & 0.225 & 0.230 & 0.240 & 0.291 & 0.347 & 0.441 & 0.334 & 0.299 & \\
\hline
\end{tabular}

